\title{
PRODUÇÃO DE MUDAS DE PARICÁ COM ESCÓRIA, INOCULADAS COM FUNGOS MICORRÍZICOS ARBUSCULARES NA REABILITAÇÃO DE ÁREAS DEGRADADAS
}

\author{
Eliade Rocha dos Santos ${ }^{1}$; Jayane Santos Nunes ${ }^{1}$; Andréa Hentz de Mello ${ }^{2}$; Clarissa Mendes \\ Knoechelmann ${ }^{3}$; Reuel Rocha dos Santos ${ }^{4}$; Raimundo Nonato do \\ Espírito Santos; ${ }^{5}$ Ana Valéria dos Reis Pinheiro5. \\ ${ }^{1}$ Discente do curso de Agronomia da Faculdade de Ciências Agrárias da Universidade Federal do Pará, Bolsista do \\ SINDSERV, eliade_rs@hotmail.com \\ ${ }^{2}$ Professora Adjunta II da Faculdade de Ciências Agrárias da Universidade Federal do Pará, andreahentz@ufpa.com \\ ${ }^{3}$ Professora Assistente I da Faculdade de Ciências Agrária da Universidade Federal do Pará,clarissa@ufpa.br \\ ${ }^{4}$ Professor do Departamento de Mecânica; Instituto Federal de Educação, Ciência e Tecnologia do Pará - Marabá PA \\ ${ }^{5}$ Professor(a) Adjunto da Faculdade de Geologia da Universidade Federal do Pará
}

\begin{abstract}
RESUMO: A mineração causa uma série de impactos físicos ao meio, da mesma forma a produção de ferro provoca impactos, e o principal é a geração de grande quantidade de resíduos que causam poluição ambiental e visual. Um desses resíduos a escória, apresenta a capacidade de corrigir a acidez dos solos. Assim este trabalho tem o objetivo de produzir mudas de paricá (Schizolobium parahyba var. amazonicum (Huber ex Ducke) Barneby) com doses crescentes de escória, inoculadas com Fungos Micorrízicos Arbusculares (FMAs) para reabilitar essas áreas e minimizar a poluição ambiental e visual. O inóculo de FMAs foi produzido através do cultivo armadilha com Brachiaria brizantha em casa de vegetação. As mudas foram produzidas com substrato contendo solo da área de rejeito e escória, inoculadas no momento da semeadura. A escória utilizada no experimento foi obtida da empresa SI NOBRAS. As sementes de Paricá passaram pelo processo de quebra de dormência. O delineamento experimental empregado foi um fatorial utilizando o delineamento inteiramente casualizado (DIC). Os dados foram processados e avaliados quanto a teste de média (t) a $1 \%$ e $5 \%$ e regressão. As variáveis mostraram níveis significativos a nível de $1 \%$ no fator escória. As plantas inoculadas com fungos micorrízicos arbusculares responderam positivamente as doses de escória.
\end{abstract}

PALAVRAS-CHAVE: insumos biológicos, resíduo industrial, restabelecimento.

\section{SEEDLING PARICÁ PRODUCTION WITH SLAG, INOCULATED MYCORRHIZAL FUNGI IN REHABILITATION OF DEGRADED AREAS}

\begin{abstract}
The mining causes a number of physical impacts to the environment, of the same way the iron production causes impacts, and the main is the generation of large amounts of wastes that cause environmental and visual pollution. One of these wastes to slag, presents the ability to correct the soil acidity. Then this work has the objective of to produce seedlings of paricá(Schizolobium parahyba var. amazonicum (Huber ex Ducke) Barneby) with increasing doses of slag, inoculated with Arbuscular Mycorrhizal Fungi (AMF) to rehabilitate these areas and minimize environmental and visual pollution. The AMF inoculum was produced by cultivating trap with Brachiaria brizantha in a greenhouse. The seedlings were produced with substrate containing soil in the area of tailings and slag, inoculated at planting. The slag used in the experiment was obtained from the company SI NOBRAS. The Paricá seeds passed through the process of breaking dormancy. The experimental design was a factorial using a completely randomized design (CRD). The data were processed and evaluated for the test average (t) $1 \%$ and $5 \%$ and regression. The variables showed significant levels of $1 \%$ in slag factor. The plants inoculated with arbuscular mycorrhizal fungi responded positively the doses of slag.
\end{abstract}

KEY-WORDS: biological supplies, industrial wastes, restoration.

Agroecossistemas, v. 3, n. 1, p. 83-89, 2011 


\section{INTRODUÇÃO}

A degradação de uma área ocorre quando houver alterações físicas, químicas e biológicas de forma a prejudicar o meio ambiente e o potencial sócio econômico da área. Na cidade de Marabá, a atividade de extração de argila causa tal degradação.

A região amazônica é caracterizada por ter solos pobres em nutrientes disponíveis para as plantas, por haver a lixiviação das bases e conseqüentemente sua acidez. O fósforo (P) é um dos elementos pouco encontrados de forma disponível nesses solos (SANTOS et al., 2010).

Em Marabá, além de uma intensa atividade mineradora, há também as empresas siderúrgicas que na produção de ferro gusa (matéria prima na produção do aço) liberam alguns resíduos. Um desses resíduos, a escória, tem diversas aplicações, entre elas agronômica que é a capacidade de corrigir a acidez do solo, pois em sua composição química encontra-se o Óxido de Cálcio $(\mathrm{CaO})$.

O processo de recuperação de áreas degradadas requer conhecimento do histórico da área a ser recuperada.

$\mathrm{O}$ uso de FMAs associados às raízes das culturas beneficia nutricionalmente as plantas, aumentando a interceptação do $\mathrm{P}$ difundido na solução do solo, alcançando áreas do solo inacessíveis às raízes e elevando a absorção de nutriente (CAMARGO, 2009).

O paricá (Schizolobium parahyba var. amazonicum (Huber ex Ducke) Barneby) é uma espécie de rápido crescimento, (DUCKE, 1949) que pode alcançar $40 \mathrm{~m}$ de altura e $100 \mathrm{~cm}$ de DAP.

Diante da necessidade da recuperação, este trabalho, teve como objetivo a produção e avaliação de mudas de Paricá com doses crescentes de escória inoculadas com fungos micorrízicos arbusculares (FMA's), para reabilitar a área degradada pela extração da argila, em um curto período de tempo.

\section{MATERIAL E MÉTODOS}

O trabalho foi conduzido na casa de vegetação da Faculdade de Ciências Agrárias de Marabá da Universidade Federal do Pará.

A escória utilizada no experimento foi obtida da empresa Siderúrgica Norte Brasil S.A. (SINOBRÁS).

O inóculo foi produzido através do cultivo armadilha, com Brachiaria brizantha em areia de praia em casa de vegetação.

A extração de esporos de FMA's no solo consistiu basicamente em extraí-los de $50 \mathrm{~g}$ de solo pela técnica de peneiramento úmido de (GERDEMANN; NICOLSON, 1963) e centrifugação em água e sacarose a $40 \%$ (JENKINS, 1964).

Foi utilizado o inóculo puro de Gigaspora margarita e Glomus clarum contendo aproximadamente 20 esporos de cada espécie, inoculados no momento da semeadura.

As sementes de Paricá passaram pelo processo de quebra de dormência, que consistiu em: colocar as sementes em água quente $\left(80^{\circ} \mathrm{C}\right)$ e permanecer por 24 horas. As mudas foram produzidas em sacos plásticos preto de 
polietileno, com substrato contendo solo (local de extração de argila) e escória de siderurgia (duas doses $10 \%$ e $40 \%$ ), utilizando duas sementes de cada espécie por recipiente, sendo regadas três vezes ao dia. A inoculação dos FMAs foi efetuada no momento da semeadura e aos 30 e 60 dias após a germinação foram avaliadas quanto aos parâmetros de crescimento como altura, número de folhas, número de folíolos, diâmetro do coleto.

O delineamento experimental empregado foi um fatorial utilizando o delineamento inteiramente casualizado (DIC), com uma espécie vegetal, três tratamentos de inoculação, 2 doses de escória e 10 repetições $(1 \times 3 \times 2 \times 10)$ totalizando 60 mudas.

Os dados foram processados e avaliados quanto a teste de média (t) a $1 \%$ e $5 \%$ e regressão, segundo metodologia descrita no software aplicativo SISVAR (FURTADO, 2000).

\section{RESULTADOS E DISCUSSÃO}

Um resumo das análises de variância de todas as variáveis analisadas está descrito na tabela 1. Verifica-se que as variáveis, número de folhas, folíolos e diâmetro do coleto mostraram níveis significativos a $1 \%$ de probabilidade no fator escória. A interação entre o fator inóculo e as avaliações teve nível significativo de $5 \%$ de probabilidade. As avaliações realizadas obtiveram resultados expressivos a nível de $1 \%$ de probabilidade considerando os fatores, inoculação e escória.

Os efeitos dos tratamentos mostraram-se significativos em relação ao crescimento das plantas.

Tabela 1. Esquema da análise de variância para o delineamento inteiramente casualizado, no esquema de parcela subdividida no tempo, com fatorial na parcela, considerando as variáveis: número de folhas, folíolos, altura e diâmetro do coleto.

\begin{tabular}{|c|c|c|c|c|c|}
\hline \multirow[b]{2}{*}{ F.V. } & \multirow[b]{2}{*}{ GL } & \multicolumn{4}{|c|}{ QUADRADO MÉDIO } \\
\hline & & $\mathrm{N}^{\mathrm{o}}$ de folhas & Folíolos & Altura & $\begin{array}{l}\text { Diâmetro do } \\
\text { Coleto }\end{array}$ \\
\hline INÓCULO (I) & 1 & 16,875 & 388,800 & 26,226 & 0,007 \\
\hline ESCÓRIA (E) & 2 & $50,033 * *$ & $23122,358 * *$ & 18,693 & $1,623 * *$ \\
\hline I x E & 2 & 2,800 & 943,27 & $165,727 * *$ & 0,017 \\
\hline Erro (a) & 54 & 7,939 & 4339,801 & 17,873 & 0,053 \\
\hline Avaliação (A) & 1 & $190,008 * *$ & $193603,33 * *$ & $525,426 * *$ & $2,437 * *$ \\
\hline$A \times I$ & 1 & 1,875 & 3696,300 & 0,102 & $0,290 *$ \\
\hline$A \times E$ & 2 & 25,833 & 12103,408 & 21,847 & $0,672 * *$ \\
\hline$A \times I \times E$ & 2 & 6,300 & 1373,025 & 43,801 & 0,116 \\
\hline Erro (b) & 54 & 8,895 & 4126,009 & 14,858 & 0,052 \\
\hline \multicolumn{2}{|c|}{ CV $1(\%)$} & 24,95 & 33,23 & 16,32 & 15,00 \\
\hline \multicolumn{2}{|c|}{ CV 2(\%) } & 26,03 & 32,41 & 14,88 & 14,90 \\
\hline
\end{tabular}

* Significativo a $5 \%$.

** Significativo a $1 \%$. 
A análise de regressão para o Fator Escória, considerando a variável Número de Folhas (Figura 1), apontou que quanto maior a dose de escória maior o número de folhas encontradas nas plantas. Ao comparar as médias das duas avaliações obteve-se uma diferença mínima significativa de 1,09 que expressa a diferença das plantas com 30 e 60 dias em casa de vegetação.

Modelo de Regressão para o Fator Escória

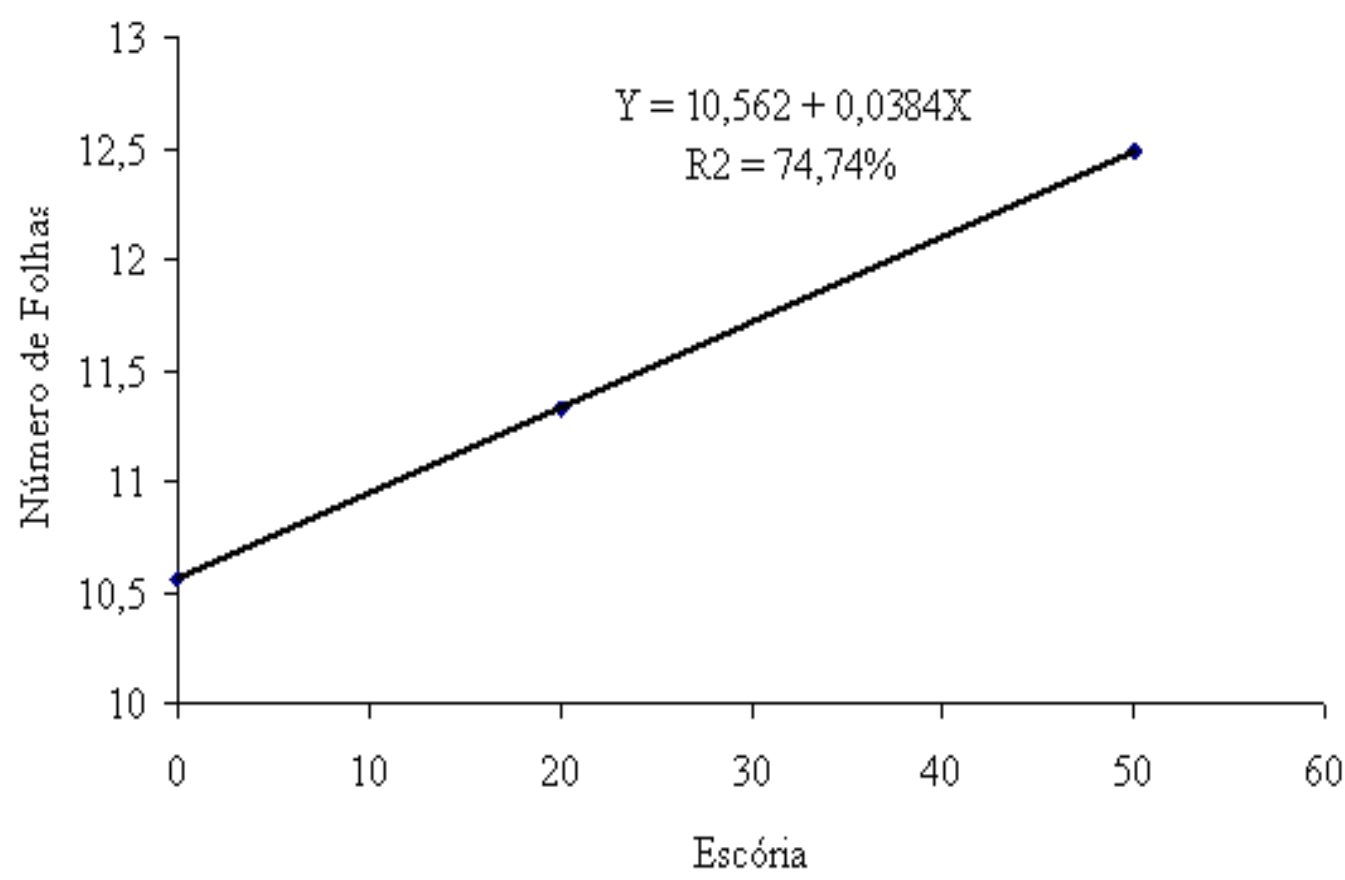

Figura 1. Análise de regressão para o Fator Escória, considerando a variável: Número de Folhas.

A análise de regressão para o Fator Escória, considerando a variável Folíolos (Figura 2), mostrou que com doses crescentes de escória o fator folíolo também é crescente. A comparação de médias demonstra que houve diferença significativa entre os tratamentos (dose menor e dose maior de escória) essa diferença foi obtida através do teste $\mathrm{t}$ a $5 \%$ de probabilidade no valor de 23,51 . 
Modelo de Regressão para o Fator Escória

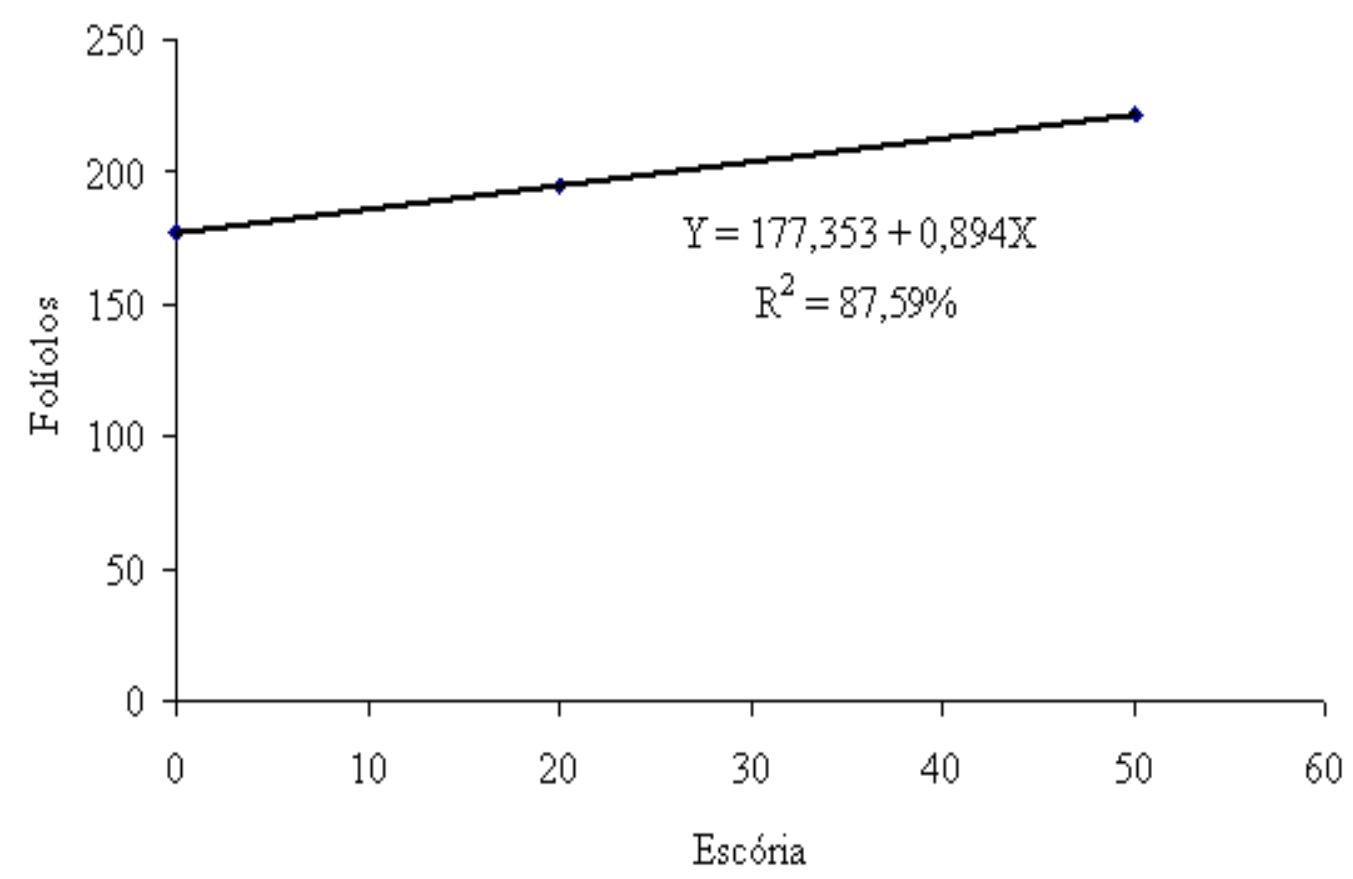

Figura 2. Análise de regressão para o Fator Escória, considerando a variável Folíolos.

A altura das plantas foi avaliada desenvolvimento quando comparadas as sem considerando a inoculação e as doses de inoculação considerando a variável altura. escória conforme tabela 2. As testemunhas inoculadas mostraram maior

Tabela 2. Teste de comparação de médias entre o uso e não de inoculo para os diferentes níveis de escória, quanto à variável altura.

\begin{tabular}{lccc}
\hline INÓCULO & \multicolumn{3}{c}{ ESCÓRIA } \\
\cline { 2 - 4 } & 0 & 20 & 50 \\
\hline Presença & $24,19 \mathrm{~b}$ & $25,61 \mathrm{a}$ & $29,30 \mathrm{a}$ \\
Ausência & $27,04 \mathrm{a}$ & $25,20 \mathrm{a}$ & $24,06 \mathrm{~b}$ \\
\hline & \multicolumn{2}{c}{ Diferença mínima significativa $=2,68$} \\
\hline
\end{tabular}

O teste de comparação de médias entre as duas avaliações e os diferentes níveis de escória mostra que houve diferença significativa entre a primeira e a segunda avaliação nas testemunhas e nas mudas com a dose mínima de escória. O tratamento com a dose maior não apresentou alteração 
significativa de acordo com o teste $\mathrm{t}$ ao nível de $5 \%$ de probabilidade conforme tabela 3 .

A análise de regressão (Figura 3) mostra que quanto maior a dose de escória maior o diâmetro do coleto, nas duas avaliações realizadas.

Tabela 3. Teste de comparação de médias entre as duas avaliações para os diferentes níveis de escória, quanto à variável Diâmetro do Coleto.

\begin{tabular}{lccc}
\hline Avaliação & \multicolumn{3}{c}{ Escória } \\
\cline { 2 - 4 } & 0 & 20 & 50 \\
\hline Primeira & $1,26 \mathrm{~b}$ & $1,17 \mathrm{~b}$ & $1,77 \mathrm{a}$ \\
Segunda & $1,58 \mathrm{a}$ & $1,69 \mathrm{a}$ & $1,78 \mathrm{a}$
\end{tabular}

Diferença mínima significativa $=2,68$

Regressão para Escória, considerando a primeira e segunda avaliação

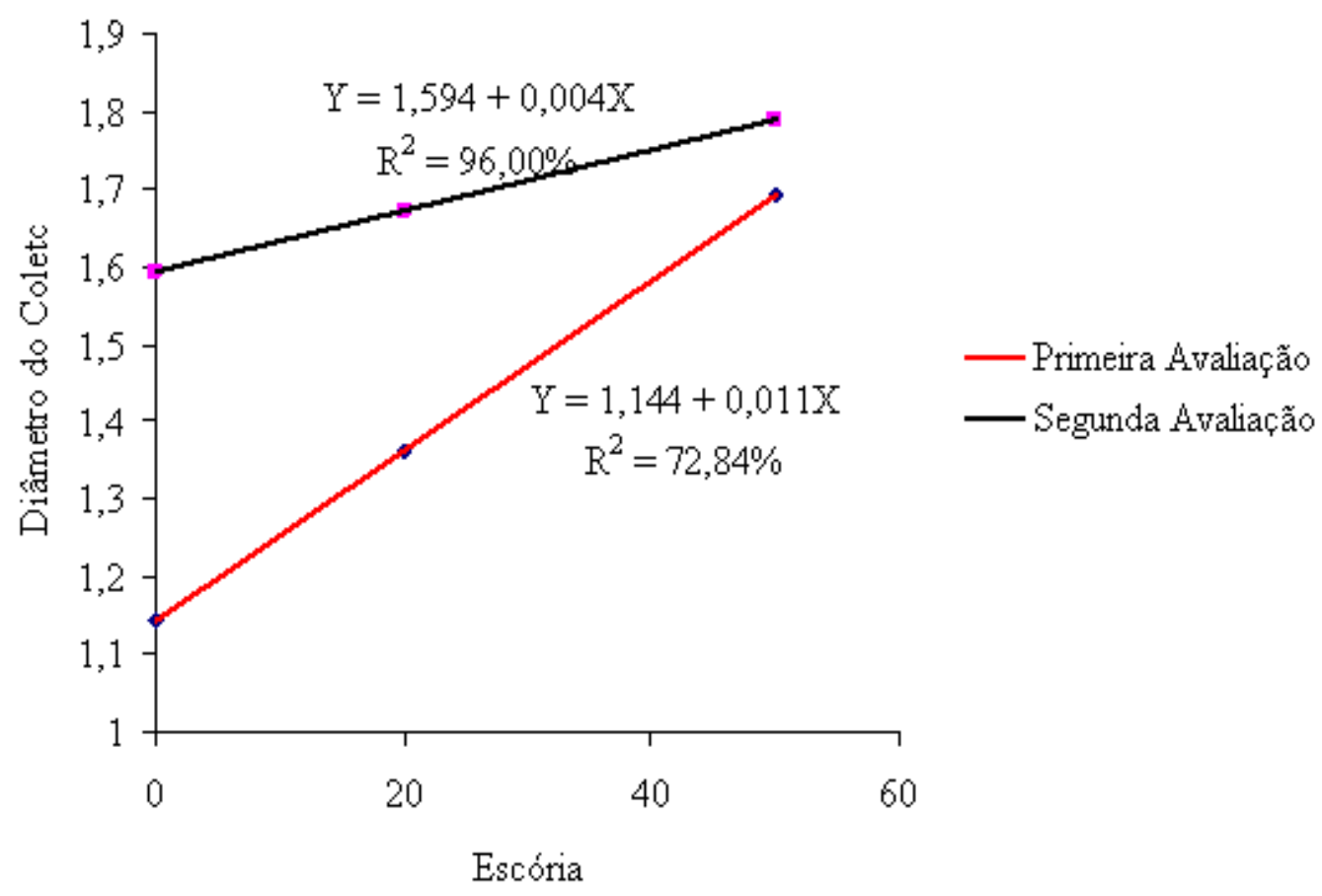

Figura 3. Análise de regressão para o Fator Escória, considerando a variável Diâmetro do Coleto. 


\section{CONCLUSÕES}

As plantas inoculadas com fungos micorrízicos arbusculares apresentaram crescimento maior em relação às plantas não inoculadas.

O paricá respondeu positivamente as doses crescentes de escória.

\section{REFERÊNCIAS}

CAMARGO, A.B. Escória de siderurgia e a nutrição fosfatada de milho inoculado com fungos micorrízicos arbusculares. Seropédica: UFRRJ, 2009.

DUCKE, A. As leguminosas da Amazônia brasileira: notas sobre a flora neotrópica II. Belém: Instituto Agonômico do Norte, 1949. 248p. (Boletim Técnico, 18)

FURTADO, D.F. Sistemas de Análise estatística para dados balanceados. Lavras:UFLA/DEX/SISVAR, 145p, 2000.

GERDEMAN, J. W.; NICOLSON, T.H. Spores of mycorrhizal Endogone speciies extracted from soil by wet and decanting. Trans.Br.Myc.Soc., v.46, 1963.p.235-244.

JENKINS, W.R. A rapid centrifugal-flotation technique for separating nematodes from soil. PI. Dis. Rep., v.48, p.692, 1964.

SANTOS, E.R.; NUNES, J.S.; HENTZ, A.M.; KNOECHELMANN, M.C.; SANTO, R.N.E.; PINHEIRO, A.V.R. Produção e avaliação de mudas de espécies arbóreas inoculadas com fungos micorrízicos para atuar na reabilitação de áreas impactadas pela extração de argila em
Marabá-Pa. In: REUNIÃO BRASILEIRA DE MANEJO E CONSERVAÇÃO DO SOLO E DA ÁGUA. 18., 2010. Anais. Teresina, Sociedade Brasileira de Ciência do Solo, 2010. CD ROM 